\title{
Undertreatment of COPD: a retrospective analysis of US managed care and Medicare patients
}

\author{
Barry Make' \\ Michael P Dutro 2 \\ Ryne Paulose-Ram² \\ Jenö P Marton ${ }^{2}$ \\ Douglas W Mapel $^{3}$
}

'National Jewish Health, Denver, CO, ${ }^{2}$ Pfizer Inc, New York, NY, ${ }^{3}$ Lovelace Clinic Foundation, Albuquerque, NM, USA
Correspondence: Michael P Dutro Pfizer Inc, 235 E 42nd Street, Mailstop 235/7/I6, New York, NY I00 I7, USA $\mathrm{Tel} / \mathrm{Fax}+$ I 5057972934

Email michael.dutro@pfizer.com
This article was published in the following Dove Press journal: International Journal of COPD

17 January 2012

Number of times this article has been viewed

Background: We investigated a large population of patients with chronic obstructive pulmonary disease (COPD) to determine their frequency of medication use and patterns of pharmacotherapy.

Methods: Medical and pharmacy claims data were retrospectively analyzed from 19 health plans ( $>7.79$ million members) across the US. Eligible patients were aged $\geq 40$ years, continuously enrolled during July 2004 to June 2005, and had at least one inpatient or at least two outpatient claims coded for COPD. As a surrogate for severity of illness, COPD patients were stratified by complexity of illness using predefined International Classification of Diseases, Ninth Revision, Clinical Modification, Current Procedural Terminology, Fourth Edition, and Healthcare Common Procedure Coding System codes.

Results: A total of 42,565 patients with commercial insurance and 8507 Medicare patients were identified. Their mean age was 54.7 years and 74.8 years, and $48.7 \%$ and $46.9 \%$ were male, respectively. In total, $66.3 \%$ of commercial patients $(n=28,206)$ were not prescribed any maintenance COPD pharmacotherapy (59.1\% no medication; $7.2 \%$ inhaled short-acting $\beta 2$-agonist only). In the Medicare population, $70.9 \%(n=6031)$ were not prescribed any maintenance COPD pharmacotherapy ( $66.0 \%$ no medication; $4.9 \%$ short-acting $\beta 2$-agonist only). A subset of patients classified as high-complexity were similarly undertreated, with 58.7\% (5358/9121) of commercial and $68.8 \%(1616 / 2350)$ of Medicare patients not prescribed maintenance COPD pharmacotherapy. Only $18.0 \%$ and $9.8 \%$ of diagnosed smokers in the commercial and Medicare cohorts had a claim for a smoking cessation intervention and just $16.6 \%$ and $23.5 \%$, respectively, had claims for an influenza vaccination.

Conclusion: This study highlights a high degree of undertreatment of COPD in both commercial and Medicare patients, with most patients receiving no maintenance pharmacotherapy or influenza vaccination.

Keywords: managed care, chronic obstructive pulmonary disease, health care utilization, quality of care

\section{Introduction}

The World Health Organization estimates chronic obstructive pulmonary disease (COPD) to be the fourth leading cause of death, accounting for at least $5 \%$ of all deaths worldwide (about 3.02 million). ${ }^{1}$ This is likely an underestimate of COPD mortality, given that COPD patients often have a high number of comorbidities and complications, ${ }^{2,3}$ and airflow obstruction is an important contributor to other causes of morbidity and mortality.,

Advances in pharmacotherapy and improvements in COPD disease management have brought about the realization that COPD is a preventable and treatable disease. ${ }^{2}$ 
These advances have also resulted in the development of COPD diagnosis and treatment guidelines, ${ }^{6-9}$ which are widely available to health care practitioners. Treatment guidelines aim to increase awareness of COPD and improve patient management and outcomes. For example, the Global Initiative for Chronic Obstructive Lung Disease (GOLD) guidelines recommend that an effective COPD management plan should include assessment and monitoring of the disease, reduction in risk factors, management of stable COPD, and management of exacerbations. ${ }^{9,10}$

Despite the widespread availability of evidence-based guidelines, survey results suggest that practitioners have major gaps in their knowledge of the core elements of COPD management, with at least $50 \%$ reportedly unaware of guidelines for COPD diagnosis and treatment. ${ }^{11}$ This lack of knowledge of recommended treatment may lead to suboptimal management of COPD patients in the primary care setting. COPD is a progressive illness with worsening symptoms, and therefore patients need to be actively prescribed appropriate therapies and to have ongoing assessments to manage their COPD and improve their health status.

In this retrospective analysis of managed care patients, we sought to document and evaluate patterns of medication utilization and medication-related assessments recorded for COPD patients. Medication utilization, adherence, and indicators of treatment and care were analyzed to assess treatment of COPD patients based on recognized guidelines. A subgroup of COPD patients with the most severe or complex COPD were identified and analyzed to determine if COPD severity changes the patterns of medication use in this cohort of commercial and Medicare patients.

\section{Materials and methods Study design}

Continuously eligible populations from commercial, Medicare, and Medicaid membership of large, national US health plans including 12.4 million covered lives were identified from the PharMetrics database (Watertown, MA). The database included 19 health plans across the US: 3.2 million from the Northeast, 6.4 million from the Midwest, 1.8 million from the South, and 0.7 million from the West. The plans varied in size: six were $<200,000$ covered lives, nine were between 200,001 and one million covered lives, and four were over one million covered lives. ${ }^{12}$ Pharmacy and medical claims from the 7.79 million members who were continuously eligible during the study period (July 2004 and June 2005) were retrospectively analyzed for COPD cohorts. Medicaid (a government-funded program primarily for indigent younger adults and children) claims data were analyzed, but are not reported here because only 485 of 83,007 patients were identified as having COPD. Patient stratification is outlined in Figure 1. The commercial population represented employees and their eligible dependants from employer-based health insurance product offerings, including health maintenance organization, preferred provider organization, and point of service plans. Medicare is a government-sponsored health care program for patients aged $\geq 65$ years and for others with certain disabilities. The Medicare population in this analysis includes persons who chose to have this benefit managed by a private insurance company. Additional details of the populations studied in this analysis have been reported elsewhere. ${ }^{12}$

\section{Identification of populations}

Patients were identified as having COPD if they were aged $\geq 40$ years and had any one of the following:

- One inpatient hospitalization or one emergency room encounter with a COPD diagnosis (2004 International Classification of Diseases, Ninth Revision, Clinical Modification [ICD-9-CM] codes 491.x [chronic bronchitis], 492.x [emphysema], or 496 [chronic airway obstruction]) listed in any position as a discharge diagnosis

- Two professional claims, with different dates of services, with a COPD diagnosis listed in any position

- A COPD-related surgical procedure (eg, lung volume reduction) listed on either a professional or facility claim. COPD-related surgical procedures included open excision

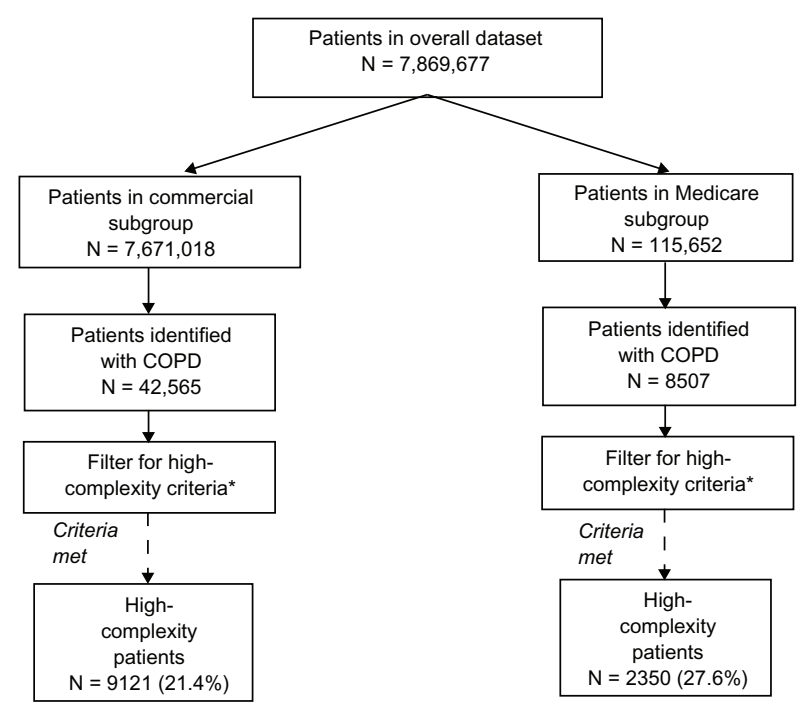

Figure I Flow of patients through the study. Complexity is used as a surrogate for COPD disease severity, and methodology for classification is described in full elsewhere. ${ }^{12}$

Abbreviation: COPD, chronic obstructive pulmonary disease. 
plication of bullae of lung, open excision plication of emphysematous lung(s) for lung volume reduction, and thoracoscopy with excision plication of bullae of lung.

\section{Medication utilization}

Use of COPD medication(s) was analyzed during the one-year period based on pharmacy claims in the datasets. A patient was considered to be taking a medication if they had at least one filled prescription for that medication product during the one-year study period. The following medications were considered maintenance COPD pharmacotherapy: long-acting $\beta 2$-agonist bronchodilators (LABA), shortacting or long-acting anticholinergic bronchodilators (SAAC and LAAC, respectively), methylxanthine bronchodilators (theophylline), and inhaled corticosteroids. As per the GOLD guidelines, short-acting $\beta 2$-agonists (SABAs) were considered symptomatic medications or rescue drugs. ${ }^{10}$ Medication utilization is reported in two ways:

- Medications of interest, which represent the number of COPD patients who filled at least one prescription for a defined medication class (or fixed-dose combination) of a respiratory or nonrespiratory medication (eg, antimicrobials, narcotic analgesics, diuretics, antidepressants, anxiolytics/sedatives, gastrointestinal antisecretory/antiulcer agents, $\beta$-blockers, antihistamines [not part of cough/cold preparations], smoking deterrents/nicotine replacements, gastrointestinal promotility agents, antiarrhythmia agents) during the one-year study period. Reporting in this manner is not mutually exclusive and patients could be receiving more than one medication of interest.

- Medication patterns, which represent the number of COPD patients who filled at least one prescription for each defined respiratory drug class or drug class combination during the one-year study period. Reporting in this manner is mutually exclusive and patients could only be classified as receiving one medication pattern. Medication patterns are used to evaluate the proportion of patients who received single or multiple maintenance COPD medications and for identifying patients receiving single or multiple therapies during the one-year study period as well as those receiving no therapy or SABA therapy alone.

To illustrate the differences between these two methods of reporting, a patient who received an inhaled anticholinergic and an inhaled corticosteroid during the study period was reported in both classes in medications of interest, but only in the anticholinergic + inhaled corticosteroid category of medication patterns.
In order to characterize further medication use in this population of COPD patients, the following were also assessed: claims for smoking cessation therapy in COPD patients documented to be current smokers (based on current tobacco use using ICD-9-CM codes); use of a maintenance COPD pharmacotherapy within 45 days following a hospitalization for a COPD exacerbation; ${ }^{13}$ and proportion of patients vaccinated against influenza.

\section{High-complexity criteria for medication pattern reporting}

The guidelines are clear that patients with more severe disease should receive maintenance COPD pharmacotherapy. ${ }^{10} \mathrm{We}$ therefore conducted an analysis of a subset with likely more severe disease. Claims data do not contain pulmonary function test values, and it was therefore not possible to assess COPD severity according to the GOLD guidelines. ${ }^{10}$ Instead, a claimsbased classification of COPD complexity was used to serve as a surrogate for COPD disease severity. The methodology for this has been described fully elsewhere. ${ }^{12}$ For this analysis, comorbid respiratory conditions and medical procedures occurring during the study period were used to assign patients to a high complexity subset, based on selected diagnostic, therapeutic, procedures, and services codes (2004 ICD-9-CM, Current Procedural Terminology, Fourth Edition, and Healthcare Common Procedure Coding System). ${ }^{12}$ For example, a patient with a claim for tuberculosis, malignant neoplasm, or cor pulmonale was classified as high complexity. A medications patterns analysis is reported for this high-complexity subset.

\section{Adherence}

Adherence to prescribed medications was estimated using pharmacy claims by calculating a medication possession ratio (MPR), defined as the total days of medication supplied in all prescription fills/total days between the first and last fill + days supplied in last prescription. MPR is a commonly used metric to assess adherence/compliance. ${ }^{14}$ Adherence with noninhaled medications (tablets, capsules, liquids) was calculated using the actual reported days of supply from the claims data. However, because the days of supply reported in pharmacy claims for inhaled medication prescriptions is often unreliable, the number of "days supplied" for inhaled medications was assigned a value based on average adult doses (in number of puffs) for each product and the number of puffs per container. Adherence to each respiratory medication is reported as the average MPR for all patients receiving two or more prescriptions of a relevant medication. MPR was only calculated for maintenance COPD medications. 


\section{Data collection and outcome measures}

DTEC ${ }^{\text {тм }}$ software (Version 3.3, Pfizer, New York, NY) was used to integrate administrative data and claims files, identify and stratify patients with COPD, as well as to characterize demographics, comorbidities (respiratory and nonrespiratory), and utilization of medications. All analyses were specified prior to the study and programmed in the software. ${ }^{12}$ These analyses, including rationale for complexity stratification, were developed by a panel of experts including pulmonologists, outcomes researchers, and claims-based research consultants. ${ }^{12}$ They were developed based on information from accepted guidelines, ${ }^{9,15}$ but also incorporate the previous experiences of the panel in claims-based research. While DTEC (a proprietary software program) was used for these analyses, the algorithms for the data reported have been specifically outlined and published previously, ${ }^{12}$ in order that they may be used in other claims querying systems.

Claims data during the 1 -year study period were analyzed and are presented as means with standard deviations. Categorical data are presented as numbers and percentages. The database was compiled in accordance with all aspects of the Health Information Portability and Accountability Act of 1996.

\section{Results}

\section{Identification of COPD population}

Of the 7,869,677 patients in the overall dataset, 42,565 commercial and 8507 Medicare patients were identified as having COPD (Figure 1). Among these two groups, $21.4 \%$ of commercial $(9121 / 42,565)$ and $27.6 \%$ of Medicare patients (2350/8507) were categorized as high-complexity, based on comorbid respiratory and nonrespiratory conditions and claims for procedures and services. ${ }^{12}$

\section{Population characteristics}

Patients with COPD from the commercial and Medicare data sets had a mean age of 54.7 years and 74.8 years, respectively, and approximately half were male (Table 1). The most common comorbidity was hypertension in both data sets $(55.2 \%$ commercial; $71.6 \%$ Medicare) followed by dyslipidemia (48.2\% commercial; $47.3 \%$ Medicare). The majority of patients recorded at least one office visit/consultation $(98.7 \%$ commercial; $96.4 \%$ Medicare) with a mean of 11.3 visits in the commercial group and 11.5 visits in the Medicare group during the one-year study period. More than half (53.9\%) of the Medicare cohort and nearly $40 \%$ of the commercial cohort (39.8\%) were hospitalized at least once for any reason during the study period. In total, 1651 Medicare patients (19.4\%) and 5922 commercial patients (13.9\%) were hospitalized at least once due to COPD. Additional details describing these COPD populations have been published in full elsewhere. ${ }^{12}$

\section{Medication utilization}

\section{Medications of interest}

The proportion of COPD patients in the commercial and Medicare populations receiving different classes of respiratory and nonrespiratory drugs are shown in Table 2. Oral corticosteroids and SABAs were the most commonly filled respiratory medications in commercial $(30.1 \% ; 30.0 \%)$ and Medicare $(20.9 \% ; 25.5 \%)$ populations, respectively. Systemic antibiotics or antimicrobials were the most common non-COPD medications used in both data sets, prescribed to $57.7 \%$ and $40.2 \%$ of the commercial and Medicare populations, respectively.

\section{Medication patterns}

Figure 2 shows patterns of medication use, and indicates that the majority of patients in both cohorts did not receive any

Table I Patient characteristics

\begin{tabular}{|c|c|c|c|c|}
\hline & \multicolumn{2}{|l|}{ Commercial } & \multicolumn{2}{|l|}{ Medicare } \\
\hline & $\begin{array}{l}\text { All } \\
(n=42,565)\end{array}$ & $\begin{array}{l}\text { High complexity } \\
\text { (n = 9121; 2I.4\%) }\end{array}$ & $\begin{array}{l}\text { All } \\
(n=8507)\end{array}$ & $\begin{array}{l}\text { High complexity } \\
(n=2350 ; 27.6 \%)\end{array}$ \\
\hline \multicolumn{5}{|l|}{ Age, years } \\
\hline Mean \pm SD & $54.7 \pm 6.1$ & $55.1 \pm 6.0$ & $74.8 \pm 7.3$ & $74.6 \pm 7.6$ \\
\hline \multicolumn{5}{|l|}{ Age, n (\%) } \\
\hline 40-44 years & $2960(7.0)$ & $572(6.3)$ & $15(0.2)$ & $3(0.1)$ \\
\hline $45-54$ years & 14,432 (33.9) & 2911 (31.9) & $125(1.5)$ & $44(1.9)$ \\
\hline $55-64$ years & $25,173(59.1)$ & $5638(61.8)$ & $460(5.4)$ & $155(6.6)$ \\
\hline $65-74$ years & $0(0)$ & $0(0)$ & 3367 (39.6) & $896(38.1)$ \\
\hline $75-84$ years & $0(0)$ & $0(0)$ & $3625(42.6)$ & $1005(42.8)$ \\
\hline$\geq 85$ years & $0(0)$ & $0(0)$ & 915 (10.8) & $247(10.5)$ \\
\hline Gender, \% male & 48.7 & $49.3 \%$ & 46.9 & $48.8 \%$ \\
\hline
\end{tabular}

Abbreviation: SD, standard deviation. 
Table 2 Medications of interest: COPD patients

\begin{tabular}{|c|c|c|}
\hline Medication group & Commercial $(n=42,565)$ & Medicare $(n=8507)$ \\
\hline \multicolumn{3}{|l|}{ Respiratory medications, n (\%) } \\
\hline Oral corticosteroids & $12,810(30.1)$ & $1780(20.9)$ \\
\hline SABA & $12,782(30.0)$ & $2167(25.5)$ \\
\hline ICS/ $\beta 2$-agonist combinations & $9623(22.6)$ & $1239(14.6)$ \\
\hline Ach $/ \beta 2$-agonist bronchodilator combinations & $7762(18.2)$ & $1200(14.1)$ \\
\hline Antitussives and expectorants & $5136(12.1)$ & $508(6.0)$ \\
\hline LAAC & $4917(11.6)$ & $625(7.3)$ \\
\hline Leukotriene modifiers & $4463(10.5)$ & $364(4.3)$ \\
\hline ICS & $307 \mid(7.2)$ & $665(7.8)$ \\
\hline SAAC & $2730(6.4)$ & $1024(12.0)$ \\
\hline Theophylline & $1746(4.1)$ & $266(3.1)$ \\
\hline LABA & $1052(2.5)$ & $174(2.0)$ \\
\hline \multicolumn{3}{|l|}{ Nonrespiratory medications, n (\%) } \\
\hline Systemic antibiotics/antimicrobials & $24,556(57.7)$ & $3424(40.2)$ \\
\hline Narcotic analgesics & $15,535(36.5)$ & $2085(24.5)$ \\
\hline Diuretics (all) & I I,567 (27.2) & $2490(29.3)$ \\
\hline Antidepressants & $11,929(28.0)$ & $1245(14.6)$ \\
\hline Anxiolytics/sedatives & $10,018(23.5)$ & $1547(18.2)$ \\
\hline $\mathrm{Gl}$ antisecretory/antiulcer agents & $11,080(26.0)$ & $1712(20.1)$ \\
\hline$\beta$-blocking agents & $8069(19.0)$ & $1768(20.8)$ \\
\hline Antihistamines (not part of cough/cold preparations) & $5098(12.0)$ & $542(6.4)$ \\
\hline Smoking deterrents/nicotine replacements & $3990(9.4)$ & $234(2.8)$ \\
\hline $\mathrm{Gl}$ promotility agents & $1175(2.8)$ & $150(1.8)$ \\
\hline Antiarrhythmia agents & $604(1.4)$ & $209(2.5)$ \\
\hline
\end{tabular}

Abbreviations: Ach, anticholinergics; COPD, chronic obstructive pulmonary disease; GI, gastrointestinal; ICS, inhaled corticosteroids; LAAC, long-acting anticholinergics; LABA, long-acting $\beta 2$-agonist inhaled bronchodilator; SAAC, short-acting anticholinergic; SABA, short-acting $\beta 2$-agonist bronchodilator.

maintenance COPD pharmacotherapy. Figure 2A shows that $66.3 \%$ of commercial patients $(n=28,206)$ received no maintenance COPD pharmacotherapy, including 25,157/42,565 (59.1\%) prescribed no COPD medications and 3049/42,565 (7.2\%) prescribed only inhaled SABAs. Figure 2B shows that $70.9 \%$ of Medicare patients $(n=6376)$ received no maintenance COPD pharmacotherapy, including 5615/8507 (66.0\%) prescribed no COPD medications, and 416/8507 (4.9\%) prescribed SABA only.

\section{High-complexity criteria for medication pattern reporting}

In order to evaluate medication utilization in patients with a high number of comorbidities who were more likely to be severe and compromised, we performed a similar evaluation for COPD patients who met criteria for high complexity (as a surrogate for COPD severity) ${ }^{12}$ and found similar trends. More than half of all high-complexity patients were not prescribed maintenance COPD pharmacotherapy. For the commercial population, 5358 (58.7\%) of high-complexity patients did not receive any maintenance COPD pharmacotherapy, including 4756 (52.1\%) receiving no COPD medications and $602(6.6 \%)$ receiving SABAs only. Similarly, $68.8 \%$ (1616/2350) high-complexity Medicare patients did not receive any maintenance COPD pharmacotherapy, including 1504/2350 (64.0\%) receiving no COPD medication and $112 / 2350(4.8 \%)$ receiving SABAs only.

\section{Treatment measures}

The evaluation of other measures of treatment also highlighted that COPD in both cohorts was often managed suboptimally. For example, smoking deterrents/nicotine replacement products were prescribed to less than $10 \%$ of patients in either population (commercial 9.4\% [3990/42,565] versus Medicare $2.8 \%$ [234/8507]). Indeed, of the commercial and Medicare patients diagnosed as smokers, only $18.0 \%(n=1466 / 8104)$ and $9.8 \%(n=62 / 636)$, respectively, had a claim for a smoking cessation intervention (medication or behavioral therapy) during the one-year study period. Among patients hospitalized for COPD, less than half of the commercial cohort (40.2\% [1912/4757] were prescribed bronchodilator therapy within 45 days following their hospitalization, and fewer still (29.9\% [359/1200]) of the older Medicare cohort. Furthermore, despite guidelines recommending vaccination against influenza as a risk reduction strategy for all patients with COPD, only 7070 patients $(16.6 \%)$ in the commercial cohort and 1996 patients (23.5\%) in the Medicare cohort were documented to have received the vaccine. 


\section{A}
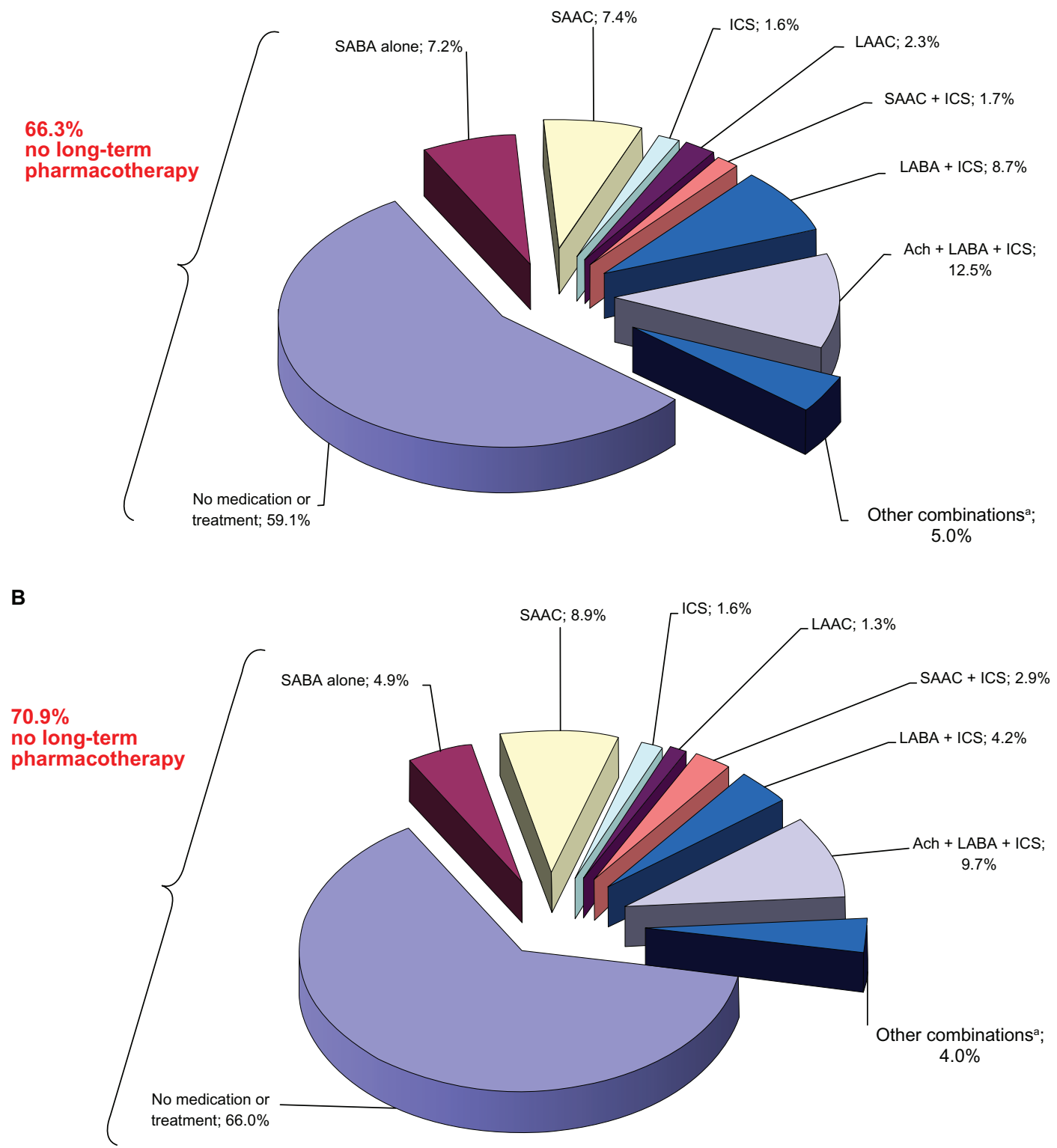

Figure 2 Respiratory medication patterns in COPD patients ${ }^{\mathrm{a}}$. (A) Commercial $(\mathrm{n}=42,565)$ and (B) Medicare $(\mathrm{n}=8507)$.

Notes: andividual medication groups are mutually exclusive. "Other combinations" includes: theophylline (methylxanthine bronchodilator) alone; short-acting anticholinergic plus theophylline; anticholinergic (short-acting or long-acting) plus theophylline plus inhaled corticosteroid; LABA; long-acting anticholinergic plus inhaled corticosteroid; SAAC; short-acting anticholinergic plus LABA; LABA plus theophylline plus inhaled corticosteroid.

Abbreviations: Ach, anticholinergics; ICS, inhaled corticosteroid; LAAC, long-acting anticholinergic; LABA, long-acting $\beta 2$-agonist inhaled bronchodilator; SAAC, shortacting anticholinergic; SABA, short-acting $\beta 2$-agonist bronchodilator.

\section{Adherence}

Medication adherence (reported as mean MPR by drug class) is provided in Table 3. While adherence was above $50 \%$ for each respiratory medication class for both cohorts, acceptable adherence (MPR $\geq 80 \%)^{14}$ was only achieved for the oral drug classes (leukotriene modifiers and theophylline). Among the inhaled agents, LAAC and LABA had the highest average adherence, while SAAC had the lowest.

\section{Discussion}

This analysis of more than 51,000 patients highlights significant undertreatment of COPD in typical US commercial and Medicare populations. The majority of diagnosed COPD patients remain undertreated with no maintenance COPD pharmacotherapy for their COPD over the one-year study period.

Inhaled bronchodilators are the accepted first-line therapies for symptomatic COPD management, because 
Table 3 Adherence (shown as average medication possession ratio) to COPD-related medications in commercial and Medicare datasets

\begin{tabular}{|c|c|c|c|c|}
\hline & \multicolumn{2}{|l|}{ Commercial } & \multicolumn{2}{|l|}{ Medicare } \\
\hline & $\begin{array}{l}\text { Evaluable } \\
\text { patients }^{\mathrm{a}} \text {, n }\end{array}$ & $\begin{array}{l}\text { Average } \\
\text { adherence, \% }\end{array}$ & $\begin{array}{l}\text { Evaluable } \\
\text { patients }^{\mathrm{a}} \text {, n }\end{array}$ & $\begin{array}{l}\text { Average } \\
\text { adherence, \% }\end{array}$ \\
\hline Leukotriene modifiers & 3457 & 82.2 & 289 & 85.2 \\
\hline Theophylline & 1344 & 81.3 & 228 & 83.4 \\
\hline LABA & 743 & 71.1 & 113 & 70.5 \\
\hline LAAC & 3250 & 73.6 & 413 & 76.9 \\
\hline ICS/ $/ 32$-agonist combinations & 6683 & 64.7 & 860 & 67.2 \\
\hline ICS & 1720 & 63.0 & 396 & 66.3 \\
\hline Ach//22-agonist bronchodilator combination & 4660 & 58.1 & 755 & 57.3 \\
\hline SAAC & 1486 & 52.3 & 674 & 51.8 \\
\hline
\end{tabular}

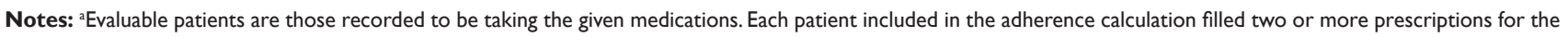
relevant medication.

Abbreviations: Ach, anticholinergics; COPD, chronic obstructive pulmonary disease; ICS, inhaled corticosteroids; LAAC, long-acting anticholinergics; LABA, long-acting $\beta 2$-agonist inhaled bronchodilators; SAAC, short-acting anticholinergics; SABA, short-acting $\beta 2$-agonist bronchodilators.

regular use can increase exercise capacity and improve health status. ${ }^{9} 16,17$ However, in the present analysis, more than two-thirds of COPD patients in the commercial population and $>70 \%$ of the Medicare population were not prescribed any long-term maintenance COPD medications. Because patients with mild COPD may appropriately not be prescribed long-term therapy according to GOLD guidelines, we also evaluated subsets of patients classified as "highcomplexity," where complexity served as a surrogate for disease severity and represented patients with the highest number of comorbid conditions and complications. ${ }^{12}$ More than half of high-complexity commercial and $69 \%$ of highcomplexity Medicare patients failed to receive any maintenance COPD pharmacotherapies. Although clinicians may be less likely to prescribe chronic COPD pharmacotherapy to older patients receiving multiple medications who may have cognitive impairment or difficulty using inhalers, the observation that $70 \%$ of older patients, such as those represented by the Medicare cohort, and $60 \%$ of high-complexity Medicare patients, did not receive even one long-term COPD pharmacotherapy is a cause for concern.

The effectiveness of recommended treatment regimens is dependent on how well patients adhere with them. Adherence to COPD medications in the present study based on medication refills was only about $50 \%$, which is comparable with other studies, ${ }^{18,19}$ but still suboptimal for patients to derive benefit from therapies being prescribed.

Our findings are particularly noteworthy given recommended guidelines outlining a clear strategy for COPD and the management of associated exacerbations. ${ }^{7,9,10,20}$ In addition, recent large, multiyear studies have shown therapies such as LAACs and LABA/inhaled corticosteroid combinations used chronically offer significant benefits to COPD patients, including a reduction in exacerbation frequency and possibly a reduction in mortality. ${ }^{21,22}$ The undermanagement highlighted here is in agreement with a survey of primary care physicians, which reported that only $35 \%$ of physicians chose a long-acting bronchodilator (recommended by GOLD) ${ }^{10}$ if use of a short-acting agent had failed to manage a patient's COPD symptoms. ${ }^{23}$ Furthermore, although $55 \%$ of physicians were aware of major COPD guidelines (GOLD or American Thoracic Society/European Respiratory Society guidelines), only $25 \%$ used them to guide decision-making. ${ }^{23}$

In addition to highlighting the suboptimal prescription of COPD medications, we also found suboptimal use of certain non-COPD maintenance pharmacotherapies. Less than $20 \%$ of COPD patients in this study were documented to have received an influenza vaccine, despite vaccination being recommended for all COPD patients to reduce exacerbation frequency. ${ }^{9}$ In addition, $82 \%$ of patients reported to be current smokers in the commercial dataset did not receive any smoking cessation intervention. Similarly, $90 \%$ of current smokers in the Medicare population did not receive smoking cessation interventions. The majority of COPD cases can be attributed to tobacco smoking, ${ }^{2}$ and smoking cessation has been shown to be the most effective method of slowing the progression of COPD. ${ }^{9,10,24}$ The evidence indicates that smoking cessation interventions, including non-nicotine pharmacotherapy, ${ }^{25,26}$ or nicotine replacement therapy, ${ }^{27}$ combined with counseling, are both effective and cost-effective. ${ }^{28-30}$

Our data should be interpreted in light of certain limitations. As with any retrospective database study, the COPD diagnosis for patients in the present study was established by the presence of claims coded for this diagnosis from health care providers, and no spirometry results are available to verify diagnosis or assess disease severity. We compensated for the latter using a surrogate, ie, COPD complexity, for severity using service and procedure codes 
and comorbid conditions selected by a panel of experts. It is possible that there is under-reporting of medication utilization because the study was limited to a one-year period, and newly diagnosed patients near the end of the inclusion period may not have had time to begin drug therapy. However, our sensitivity analyses using high-complexity patients showed similar underuse of COPD medications in this subgroup as per the whole cohort. Some diagnoses and therapies are consistently under-reported in claims data, including smoking and antismoking medications, since many health care plans do not cover these medications. Therefore, the proportion of patients recorded as smokers or taking smoking cessation therapies in the current study may actually be an underrepresentation. While this study primarily evaluates treatment with pharmacotherapy, other therapies are important in the treatment of COPD. Other health care utilization in this population including hospitalization and outpatient services such as respiratory-related equipment and supplies (including oxygen) and respiratory therapy services (including assisted ventilation) have been reported elsewhere. ${ }^{12}$ A detailed analysis of oxygen therapy in a US managed care population has also been reported previously. ${ }^{31}$

Medication adherence was estimated using reasonable assumptions for patients who filled more than two prescriptions. Patients who filled only one prescription and could be, therefore, nonadherent, were not included in the calculation. Our method of estimating the number of "days supplied" for inhaled drugs based upon recommended doses and number of puffs/inhaler, ${ }^{32}$ could be inaccurate in patients on unusual doses. While these assumptions are reasonable for the population as a whole, unusual dosing in a specific patient could result in inaccurate MPRs. We cannot account for prescriptions that were filled but not taken by the patient, or for medication samples that may have been dispensed by the health plan physicians, because these are not accounted for in claims data. Because the study was a cross-sectional analysis, no cause and effect analyses could be conducted. Analysis of the management of comorbid conditions was beyond the scope of this analysis.

Our study used data from 2004 to 2005 , prior to the publication of landmark studies, such as the Towards a Revolution in COPD Health (TORCH) and the Understanding Potential Long-Term Impacts on Function with Tiotropium (UPLIFT ${ }^{\circledR}$ ) studies, ${ }^{21,22}$ which demonstrated significant benefits of providing maintenance pharmacotherapy for COPD. ${ }^{33}$ Although we hope that the undertreatment documented in the present study has improved with the publication of these studies, the magnitude of our findings and their consistency with other reports ${ }^{34,35}$ make it very likely that a significant problem with the undermanagement of COPD patients still exists.

\section{Conclusion}

This study highlights marked undertreatment of COPD in both commercial and Medicare managed care populations. The majority of patients with COPD, even those with a high number of comorbidities, were untreated with respiratory medications. Adherence with COPD therapies was suboptimal, and related therapies, such as smoking cessation and influenza vaccinations, were underprescribed. These findings suggest that there is significant opportunity to improve the lives of patients with COPD with appropriate treatment. A major educational effort is needed to disseminate evidencebased guidelines supported by recent landmark trials to health care providers, and educate providers and patients on the long-term benefits of appropriately treating COPD.

\section{Disclosure}

This study was sponsored by Pfizer Inc. Medical writing support was provided by Karen Burrows and Jon Edwards of UBC Scientific Solutions and funded by Pfizer Inc. BM has participated in advisory boards and received honoraria for speaking from Pfizer Inc within the past 5 years. MPD and JPM are employees of and have stock options in Pfizer Inc. RP-R was an employee of Pfizer Inc at the time of the study. DWM was a paid consultant to Pfizer Inc in connection with conduct of the analysis and development of the manuscript. DWM has served as a consultant to and received research funding from Pfizer Inc, GlaxoSmithKline, and AstraZeneca. Parts of these data were presented at the American Thoracic Society meeting, May 22, 2007, San Francisco, CA.

\section{References}

1. World Health Organization (WHO). World Health Statistics 2008. COPD predicted to be third leading cause of death in 2030. Geneva: WHO; 2008. Available at: http://www.who.int/respiratory/copd/World_Health_ Statistics_2008/en/index.html. Accessed January 13, 2011.

2. Mannino DM, Buist AS. Global burden of COPD: risk factors, prevalence, and future trends. Lancet. 2007;370(9589):765-773.

3. Sin DD, Anthonisen NR, Soriano JB, Agusti AG. Mortality in COPD: role of comorbidities. Eur Respir J. 2006;28(6):1245-1257.

4. Tockman MS, Anthonisen NR, Wright EC, Donithan MG. Airways obstruction and the risk for lung cancer. Ann Intern Med. 1987;106(4): $512-518$

5. Sin DD, Man SF. Why are patients with chronic obstructive pulmonary disease at increased risk of cardiovascular diseases? The potential role of systemic inflammation in chronic obstructive pulmonary disease. Circulation. 2003;107(11):1514-1519.

6. National Collaborating Center for Chronic Conditions. Chronic obstructive pulmonary disease. National clinical guideline on management of chronic obstructive pulmonary disease in adults in primary and secondary care. Thorax. 2004;59 (Suppl 1):1-232. 
7. Celli BR, MacNee W. Standards for the diagnosis and treatment of patients with COPD: a summary of the ATS/ERS position paper. Eur Respir J. 2004;23(6):932-946.

8. O’Donnell DE, Hernandez P, Kaplan A, et al. Canadian Thoracic Society recommendations for management of chronic obstructive pulmonary disease - 2008 update - highlights for primary care. Can Respir J. 2008;15(Suppl A):1A-8A.

9. Global Initiative for Chronic Obstructive Lung Disease (GOLD). Global strategy for the diagnosis, management, and prevention of chronic obstructive pulmonary disease (updated 2010) Available at: http:// www.goldcopd.org/uploads/users/files/GOLDReport_April112011. pdf. Accessed January 13, 2011.

10. Pauwels RA, Buist AS, Calverley PM, Jenkins CR, Hurd SS. Global strategy for the diagnosis, management, and prevention of chronic obstructive pulmonary disease. NHLBI/WHO Global Initiative for Chronic Obstructive Lung Disease (GOLD) Workshop summary. Am J Respir Crit Care Med. 2001;163(5):1256-1276.

11. Rutschmann OT, Janssens JP, Vermeulen B, Sarasin FP. Knowledge of guidelines for the management of COPD: a survey of primary care physicians. Respir Med. 2004;98(10):932-937.

12. Mapel DW, Dutro MP, Marton JP, Woodruff K, Make B. Identifying and characterizing COPD patients in US managed care - a retrospective, cross-sectional analysis of administrative claims data. BMC Health Serv Res. 2011;11(1):43.

13. Stoller JK. Clinical practice. Acute exacerbations of chronic obstructive pulmonary disease. $N$ Engl J Med. 2002;346(13):988-994.

14. Halpern MT, Khan ZM, Schmier JK, et al. Recommendations for evaluating compliance and persistence with hypertension therapy using retrospective data. Hypertension. 2006;47(6):1039-1048.

15. American Thoracic Society/European Respiratory Society Task Force Standards for the Diagnosis and Management of Patients with COPD. updated September 8, 2005. Available at: http://www.thoracic.org/go/ copd. Accessed January 13, 2011.

16. Neder JA, Fuld JP, Overend T, et al. Effects of formoterol on exercise tolerance in severely disabled patients with COPD. Respir Med. 2007;101(10):2056-2064.

17. Liesker JJ, Van De Velde V, Meysman M, et al. Effects of formoterol (Oxis Turbuhaler) and ipratropium on exercise capacity in patients with COPD. Respir Med. 2002;96(8):559-566.

18. Dolce JJ, Crisp C, Manzella B, Richards JM, Hardin JM, Bailey WC Medication adherence patterns in chronic obstructive pulmonary disease. Chest. 1991;99(4):837-841.

19. Krigsman K, Nilsson JL, Ring L. Adherence to multiple drug therapies: refill adherence to concomitant use of diabetes and asthma/COPD medication. Pharmacoepidemiol Drug Saf. 2007;16(10):1120-1128.

20. The COPD Guidelines Group of the Standards of Care Committee of the BTS. BTS guidelines for the management of chronic obstructive pulmonary disease. Thorax. 1997;52 Suppl 5:1-28.
21. Tashkin DP, Celli B, Senn S, et al. A 4-year trial of tiotropium in chronic obstructive pulmonary disease. $N$ Engl J Med. 2008;359(15): 1543-1554.

22. Calverley PM, Anderson JA, Celli B, et al. Salmeterol and fluticasone propionate and survival in chronic obstructive pulmonary disease. N Engl J Med. 2007;356(8):775-789.

23. Foster JA, Yawn BP, Maziar A, Jenkins T, Rennard SI, Casebeer L. Enhancing COPD management in primary care settings. Med Gen Med. 2007;9(3):24.

24. Anthonisen NR, Connett JE, Kiley JP, et al. Effects of smoking intervention and the use of an inhaled anticholinergic bronchodilator on the rate of decline of FEV1. The Lung Health Study. JAMA. 1994;272(19):1497-1505.

25. Wagena EJ, Knipschild PG, Huibers MJ, Wouters EF, van Schayck CP. Efficacy of bupropion and nortriptyline for smoking cessation among people at risk for or with chronic obstructive pulmonary disease. Arch Intern Med. 2005;165(19):2286-2292.

26. Tashkin DP, Rennard S, Hays JT, Ma W, Lawrence D, Lee TC. Effects of varenicline on smoking cessation in patients with mild to moderate COPD: a randomized controlled trial. Chest. 2011;139(3):591-599.

27. West R, Zhou X. Is nicotine replacement therapy for smoking cessation effective in the "real world"? Findings from a prospective multinational cohort study. Thorax. 2007;62(11):998-1002.

28. Hoogendoorn M, Feenstra TL, Hoogenveen RT, Rutten-van Molken MP. Long-term effectiveness and cost-effectiveness of smoking cessation interventions in patients with COPD. Thorax. 2010;65(8):711-718.

29. Howard P, Knight C, Boler A, Baker C. Cost-utility analysis of varenicline versus existing smoking cessation strategies using the BENESCO simulation model: Application to a population of US adult smokers Pharmacoeconomics. 2008;26(6):497-511.

30. Wagena EJ, van der Meer RM, Ostelo RJ, Jacobs JE, van Schayck CP. The efficacy of smoking cessation strategies in people with chronic obstructive pulmonary disease: results from a systematic review. Respir Med. 2004;98(9):805-815.

31. Mapel DW, Robinson SB, Lydick E. A comparison of health-care costs in patients with chronic obstructive pulmonary disease using lightweight portable oxygen systems versus traditional compressed-oxygen systems. Respir Care. 2008;53(9):1169-1175.

32. US Food and Drug Administration. The National Drug Code Directory. Department of Health and Human Services. Available at: http://www. fda.gov/cder/ndc/. Accessed August 3, 2011.

33. Niewoehner DE. TORCH and UPLIFT: what has been learned from the COPD "mega-trials"? COPD. 2009;6(1):1-3.

34. Miller RM, George D, Halbert RJ. Improving the management of chronic obstructive pulmonary disease. J Healthc Qual. 2005;27(2):42-47.

35. Fromer L, Barnes T, Garvey C, Ortiz G, Saver DF, Yawn B. Innovations to achieve excellence in COPD diagnosis and treatment in primary care. Postgrad Med. 2010;122(5):150-164.
International Journal of COPD

\section{Publish your work in this journal}

The International Journal of COPD is an international, peer-reviewed journal of therapeutics and pharmacology focusing on concise rapid reporting of clinical studies and reviews in COPD. Special focus is given to the pathophysiological processes underlying the disease, intervention programs, patient focused education, and self management protocols.

\section{Dovepress}

This journal is indexed on PubMed Central, MedLine and CAS. The manuscript management system is completely online and includes a very quick and fair peer-review system, which is all easy to use. Visit http://www.dovepress.com/testimonials.php to read real quotes from published authors. 